\title{
Sphenopalatine Block for Treatment of Migraine Headache
}

\author{
Barry J Kraynack* \\ White Bear Associates, USA \\ *Corresponding author: Barry J Kraynack, White Bear Associates, LLC, Tel: 570-359-3333, USA. \\ To Cite This Article: : Barry J Kraynack. Sphenopalatine Block for Treatment of Migraine Headache. Am J Biomed Sci \& Res. 2019 - 2(5). AJBSR. \\ MS.ID.000607. DOI: 10.34297/AJBSR.2019.02.000607
}

Received: March 29, 2019 | Published: May 02, 2019

\section{Mini Review}

Migraine is a common headache and a leading cause of disability worldwide [1]. Chronic migraine (CM) burdens patients due to the headache and debilitating associated symptoms and through disability high economic costs. CM patients meet diagnostic criteria and have a minimum of headaches and symptoms 8 days a month or headaches on 15 days a month. A complete, detailed history and an in-depth physical examination with the emphasis on neurologic aspects is required in order to differentiate $\mathrm{CM}$ from other causes of headache. If indicated, other diagnostic tests may be required [2]. A multifaceted approach is used to eliminate risk factors and headache triggers. Prophylaxis and abortive approaches can be applied. Use of pharmacologic agents for the acute/chronic treatment of migraine may be limited by adverse side effects, variability if effect and efficacy, or contraindications, allergies or untoward drug -drug interactions. These factors contribute to chronicity of the headache and medication overuse headache [3].

Historically, we have considered migraine as a self-limited pain disorder that is episodic. More recently however, CM has become an end stage disorder of episodic migraine (EM). The International Headache Society suggests that CM is a complication of EM [4-6]. Indeed, other current evidence indicates that migraine may be a chronic progressive disorder characterized by escalating frequency of headache attacks, often termed transformed migraine. Munakata et al. [7] reported that transformed migraine patients missed much more work or school time. Productivity was significantly reduced. Average per-person annual total costs were 4.4-fold greater for those with transformed migraine (\$7750) versus those with EM (\$1757). Transformed migraine extracts a significant economic toll.

Approximately $15 \%$ of the world population is affected by migraine. Incidence varies by sex, age, ethnic background and geographic area. It is more common in women and reported to be disabling in $2 \%$ of the general population [2,8-13]. In the US, the National Foundation estimates that nearly 12 percent of the population experience migraine headaches. This means that nearly 40 million people in the United States have migraines. Women are about three times more likely than men to experience migraines.
Migraine is a common disabling brain disorder that affects one in seven US citizens annually. The burden of migraine is substantial, both in economic terms and for individual patients and their close family members.

Migraines are a significant source of both medical costs and lost productivity. It has been estimated that they are the most expensive neurological disorder in the European Community, costing more than €27 billion per year [14-17]. In the United States direct costs have been estimated at $\$ 17$ to 19.6 billion while indirect costs are estimated at another $\$ 15$ billion.

It is thought that as many as $20 \%$ of those with CM and one in 8 of with high headache frequency are employable but are not gainfully so [18]. CM imposes significant burdens. There may be physical, emotional, occupational, academic, social, leisure, and family systems placed on these patients. Societal burdens include those direct and indirect costs which must be paid by society through costs passed on to companies and their customers as well as health care systems and taxpayers [19].

This article provides a brief view of acute and chronic migraine treatment, using sphenopalatine (SPG) block with local anesthetics drugs only. For full anatomic details and methods, please see the reviews [20-25].

For over a hundred years, the sphenopalatine ganglion (SPG) has been utilized to treat a wide variety of pain disorders. Post-ganglionic parasympathetic, sympathetic neurons and the somatic sensory efferent nerves can all be blocked by the SPG interventions. Interventions include block with local anesthetics and neural destructive agents, radiofrequency or surgical ablation, and neurostimulation $[20,21]$. Painful conditions treated included: headache of various etiologies, trigeminal neuralgia, oral/facial pain due to cancer, tension headache in labor and post-dural puncture headache (PDPH), herpetic neuralgia of the eye and complex regional pain syndrome I and II of other body areas as well as effective pain relief in various other pain syndromes including sphenopalatine neuralgia, atypical facial pain, muscle pain, vasomotor rhinitis and eye disorders. 
Trials have shown that these pain disorders can be managed effectively with sphenopalatine ganglion blockade (SPGB). The SPG block with local anesthetics is a safe, easy to administer and costeffective method to manage acute, chronic and breakthrough pain and provides immediate relief and minimal adverse side effects [22-25]. SPG block can be performed following a simple protocol by physicians, nurse practitioners and PAs in various sites such as the office, clinic and ER department.

\section{References}

1. Stovner LJ, Hagen K, Jensen R, Katsarava Z, Lipton R, et al. (2007) The global burden of headache: A documentation of headache prevalence and disability worldwide. Cephalalgia 27(3): 193-210.

2. T J Schwedt (2014) Chronic Migraine. BMJ 348: g1416.

3. Martelletti P, Barbanti P, Grazzi L, Pierangeli G, Rainero I, et al. (2018) Consistent effects of non-invasive vagus nerve stimulation (nVNS) for the acute treatment of migraine: additional findings from the randomized, sham-controlled, double blind PRESTO trial. J headache Pain 19(1): 101

4. Cady RK, Schreiber CP, Farmer KU (2004) Understanding the patient with migraine: The evolution from episodic headache to chronic neurological disease. Headache 44: 426-435.

5. Katsarava Z, Schneeweiss S, Kurth T, Kroener U, Fritsche G, et al. (2004) Incidence and predictors for chronicity of headache in patients with episodic migraine. Neurology 62(5): 788-790.

6. Silberstein SD, Lipton RB, Saper JR (2008) Chronic daily headache including transformed migraine, chronic tension-type headache, and medication overuse headache. In: Silberstein SD, Lipton RB, Dodick DW (Eds.), Wolff's Headache and other Head Pain, $\left(8^{\text {th }}\right.$ edn), Oxford University Press, New York, USA, pp. 315-377.

7. Munakata, J, Hazard E, Serrano D, Klingman D, Rupnow MF, et al. (2009) Economic burden of transformed migraine: results from the American Migraine Prevalence and Prevention (AMPP) study. Headache 49(4): 498-508.

8. Bartleson JD, Cutrer FM (2010) Migraine update. Diagnosis and treatment. Minn Med 93(5): 36-41.

9. Vos T, Flaxman AD, Naghavi M, Lozano R, Michaud C, et al. (2012) Years lived with disability (YLDs) for 1160 sequelae of 289 diseases and injuries 1990-2010: a systematic analysis for the Global Burden of Disease Study 2010. Lancet 380 (9859): 2163-2196.

10. Stovner LJ, Zwart JA, Hagen K, Terwindt GM, Pascual J (2006) Epidemiology of headache in Europe. European Journal of Neurology 13(4): 333-345.

11. Natoli JL, Manack A, Dean B, Butler Q, Turkel CC, et al. (2010) Global prevalence of chronic migraine: a systematic review. Cephalalgia 30(5): 599-609.
12. Hershey AD (2010) Current approaches to the diagnosis and management of pediatric migraine. Lancet Neurology 9(2): 190-204.

13. Silberstein SD (2016) Considerations for management of migraine symptoms in the primary care setting. Postgraduate Medicine 128(5): 523-537.

14. Stovner LJ, Andrée C (2008) Impact of headache in Europe: a review for the Eurolight project. J Headache Pain 9(3): 139-146.

15. Mennini FS, Gitto L, Martelletti P (2008) Improving care through health economics analysis: cost of illness and headache. J Headache Pain 9(4): 199-206.

16. Stewart WF, Ricci JA, Chee E, Morganstein D, Lipton R (2003) Lost productive time and cost due to common pain conditions in the US workforce. JAMA 290(18): 2443-2454.

17. Olesen J (2005) Cost of disorders of the brain in Europe. Eur J Neurol 12(Suppl 1): 1-27.

18. Stewart WF, Wood GC, Manack A, Varon SF, Buse DC, et al. (2010) Employment and work impact of chronic migraine and episodic migraine. J Occup Environ Med 52(1): 8-14.

19. Buse D, Manack A, Serrano D, Reed M, Varon S, et al. (2012) Headache impact of chronic and episodic migraine: results from the American Migraine Prevalence and Prevention study. Headache 52(1): 3-17.

20. Ho KWD, Przkorar R, Kumar S (2017) Sphenopalatine ganglion: block, radiofrequency ablation and Ho neurostimulation-a systematic review. J Headache Pain 18(1): 118.

21. Piagkou M, Demesticha T, Troupis T, Vlasis K, Skandalakis P, et al. (2011) The pterygopalatine ganglion and its role in various pain syndromes: from anatomy to clinical practice. Pain Practice 12(5): 399-412.

22. Kraynack BJ (2017) Sphenopalatine Ganglion Block: An Underutilized Tool in Pain Management. Dev Anesthetics Pain Manag 1(1): 1-4

23. Cady R, Saper J, Dexter K, Manley HR (2015) A double-blind, placebocontrolled study of repetitive transnasal sphenopalatine ganglion blockade with tx360(®) as acute treatment for chronic migraine. Headache 55(1): 101-116.

24. Cady RK, Saper J, Dexter K, Cady RJ, Manley HR (2015) Long-term efficacy of a double-blind, placebo-controlled, randomized study for repetitive sphenopalatine blockade with bupivacaine vs. saline with the Tx360 device for treatment of chronic migraine. Headache 55(4): 529-542.

25. Candido KD, Massey ST, Sauer R, Darabad RR, Knezevic NN (2013) A novel revision to the classical transnasal topical sphenopalatine ganglion block for the treatment of headache and facial pain. Pain Physician 16(6): E769-E778. 